\title{
Review: Successful Helicobacter pylori eradication prevents ulcer recurrence
}

Laine L, Hopkins RJ, Girardi LS. Has the impact of Helicobacter pylori therapy on ulcer recurrence in the United States been overstated? A neta-analysis of rigorously designed trials. Am J Gastroenterol. 1998 Sep; $93: 1409-15$.

\section{Question}

In North American patients with dirodenal ulcers that are healed after Helicobatter pylori-eradication treatment, do uicers recur less often in those withouc H. pylorinfection than in those with persistent infection after treatment?

\section{Dala sources}

Studies were identified by searching MEDLINE (from 1983) with the terns pylori or pyloridis, ulcer, treatment, eradication, recurrence, and doubleblind; annual meeting abstracts; and bibliographies of relevant papers. Investigators and pharmaceutical manufacturers were also contacted.

\section{Study selection}

Pubished and unpublished studies were selected if they were randomized, double-blind trials of $H$. pylori-eradication treatment; used regularly scheduled endoscopy duxing $\geq 6$ months of followup; and involved patients who did not use nonsteroidal anti-inflammatory drugs and who had duodenal ulcers that were healed after $H$. pylori-eradication treatment.

\section{Commentary}

Recognition of the importance of $H$. pylori in the pathogenesis of duodenal ulcer led to the expectation that eradication of the infection would cure the disease. Indeed, the initial studies done outside of the United States showed a recurrence rate as low as $2 \%$ at 6 months after successful treatment (1). This contrasts sharply to the $18 \%$ recurrence rate in this meta-analysis of U.S. studies. What accounts for the higher prevalence of $H . p p^{\prime}$ lori-negative duodenal ulcers?

The authors speculate that the differences may reflect variations in physiologic variables, such as acid secretion, but it seems unlikely that acid secretion in U.S. patients would differ substantially from that in pa-

\section{Data extraction}

Reviewers independently extracted data on type of publication, medication type and dosage, and criteria for $H$. pylori care; they resolved disagreements by consensus. Missing data and updated results were obtained from and ambiguous data were clarified by trial investigators.

\section{Main results}

7 North American studies involving 989 patients met the inclusion criteria. 1 study was published in a peer-reviewed joumal, 4 were published in 3 abstracts, and 2 were unpublished. 4 studies were placebo-controlled. All studies tested 2 -week dual therapy for eradicating H. pylori ( 2 stadies used omeprazole plus clarithromycin, 2 used ranitidine bismuth citrate $[\mathrm{RBC}]$ plus amoxicillin, 2 used RBC plus clarithromycin, and 1 used omeprazole plus amoxicilin). After teatment, 414 of 61.9 patients with healed ulcers tested positive for H. pyloni (placebo $[n=21]$, monotherapy $[n=316]$, and dual therapy $[n=77])$. Ucer recurrence was assessed at up to 24 weeks in 6 studies and 28 weeks in

Successful $H$. pylori eradication vs persistent infection after treatment $\dagger$

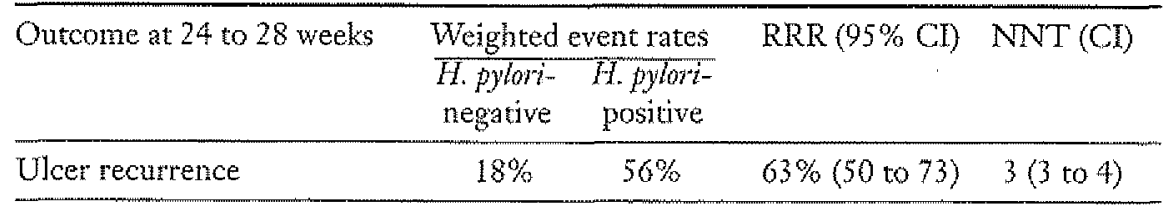

tAbbreviations defined in Glossary; RRR, NNT, and CI calculated from data in arcicle.

tients in western Europe, where many of the earlier studies were done. Another explanation is the surreptitious use of nonsteroidal anti-inflammatory drugs in U.S. patients (2). The bottom line is that eradication of $H$. pylori is a very effective therapy for duotenal ulcer but, at least in the United States, does not produce a miversal cure. Clinicians thus need to be aware that, despite successful eradication of $H$. pylori, a substantial proportion of patients with ulcer may continue to rem quire long-term acid suppression medications to control symptoms or prevent recurrent hemorrhage.
I study. Fewer patients without $H$. pylon infection had ulcer recurrence than did those with persistent $H$. pylori infection after treatment $\{P<0.001\}^{*}$ (Table). $20 \%$ (unweighted rate) of $H$. pylorinegative patients had ulcer recurrence within 6 months.

\section{Conclusions}

In patients with healed duodenal ulcers after Helicobacter fylorimeradication treatment, patients without $H$. pylori infection have fewer ulcer recurrences than do those with persistent infection. H. $p y-$ Lori eradication does not preclude ulcer recurrence in $H . p y l o r i$-negative patients. Source of funding: Not stated.

For correspondence: Dr: LA. Laine, GI Divi. sion, Department of Medicine, Univessity of Southern California Scbool of Medicine, 2025 Zonal Avenate, Los Angeles, CA 90033, USA. FAX 214-857-1571.

*p value calculated fron data in article.

Abstract and Commentary also published in ACP Jotnnal Chab. 1999;130:63.

2. Lanas AI, Remacha B, Esteva F, Sainz Risk factors associated with refractory peptic ulcers. Gastroenterology. 1995;109:1124-33. 